\title{
Poesia completa de Honório Armond: a edição de 2011
}

Eliana Scotti Muzzi Universidade Federal de Minas Gerais

\begin{abstract}
Resumo: Este artigo relata aspectos do processo editorial da Poesia completa de Honório Armond, poeta barbacenense, publicada em 2011. A edição foi preparada pelas professoras Eliana Scotti Muzzi e Nancy Maria Mendes.

Palavras-chave: Poesia brasileira, Simbolismo, Parnasianismo, Honório Armond.
\end{abstract}

A edição da Poesia completa de Honório Armond (completa até o presente momento, bem entendido) teve origem numa proposta que me fez minha colega Nancy Maria Mendes, nos idos de 2005. O meu primeiro contato com a obra do poeta - que até então desconhecia - me provocou uma reação de surpresa: uma voz diferente, forte, contestadora, inquiridora se fazia ouvir naqueles poemas. Aceitei logo o convite da colega e iniciamos assim um longo e difícil percurso que resultou nessa edição.

Logo de início, o primeiro desafio foi o acesso à única edição dos livros do autor: Ignotae Deæ, publicado em 1917; Perante o Além, em 1921; e os poemas em francês de Les Voix et les Bonheurs, em 1932. Até então, nosso contato com a obra de Honório Armond tinha se dado através de uma republicação dos três livros em um só volume, feita em comemoração ao 
centenário de nascimento do poeta, por iniciativa da Academia Barbacenense de Letras e da Prefeitura de Barbacena. Na biblioteca da Academia Mineira de Letras - onde Honório Armond ocupou, durante 30 anos, a cadeira de número 38 - e na Mineiriana, da Biblioteca Estadual Luís de Bessa, conseguimos localizar um único exemplar dos dois livros em português. Não sendo permitido o empréstimo das obras, nem mesmo para fins de edição, foi necessário fazer in loco a colação ou comparação entre os dois únicos testemunhos identificados. Embora a publicação comemorativa do centenário do poeta tenha consistido numa reprodução das edições, inclusive com a grafia da época e com os erros tipográficos que delas constavam, ainda assim foram detectados lapsos, omissões, equívocos e outras falhas. A reconstituição da primeira edição dos poemas em português constituiu, portanto, o texto-base para a nova edição. Em relação aos poemas franceses de Les Voix et les Bonheurs, o estabelecimento do texto-base foi bem mais fácil, por se ter conseguido de imediato a edição original. Ainda assim, e apesar do grande domínio do francês demonstrado pelo poeta, algumas impropriedades e pequenas incorreções demandaram a contribuição de uma colega francesa.

Como pretendíamos fazer uma edição o mais completa possível, que acrescentasse aos livros publicados poemas divulgados em outros veículos de comunicação, além de possíveis manuscritos e rascunhos, passamos à segunda e mais difícil etapa do processo: a busca e coleta desse material - ou recensio, na linguagem da crítica textual. A maior dificuldade aí encontrada foi a total inexistência de arquivo pessoal do poeta que, propositalmente ou não, nada guardou. Estava, em princípio, descartada de antemão a possibilidade de uma abordagem crítico-genética, por meio da qual os avant-textes dos poemas pudessem nos informar sobre seu processo de criação.

Enquanto tentávamos contato com familiares, amigos e contemporâneos do poeta, na expectativa de se conseguir alguma contribuição nessa área, iniciamos uma longa pesquisa, até certo ponto aleatória, em jornais e revistas da época em que houvesse algum indício de publicação de Honório Armond. Além das bibliotecas da Academia Mineira de Letras e da Mineiriana, foram consultados a Hemeroteca da Biblioteca Estadual Luís de Bessa, os arquivos da Imprensa Oficial, a Biblioteca Nacional do Rio de Janeiro, bem como a Biblioteca da Casa de Rui Barbosa e a da Academia Barbacenense de Letras. A pesquisa mais prolongada, mas que ofereceu a maior coleta, realizouse na Tipografia do jornal Cidade de Barbacena. Foi também a que ocorreu nas mais inusitadas condições: em meio ao barulho das máquinas impressoras e 
ao movimento dos tipógrafos, assentadas em precárias cadeiras ou banquinhos e tendo os enormes volumes apoiados numa escada, examinamos, página por página, todos os números desse jornal diário, de 1917 a 1958 - datas que marcam o início e o fim da atividade poética de Honório Armond. Foram encontrados 25 poemas, 15 dos quais inéditos em livro. Alguns outros foram localizados no jornal Diário de Minas e nas revistas Acaiaca, Radium e na Revista da Academia Mineira de Letras.

Durante esse tempo, foi estabelecida comunicação com a família e com pessoas que conviveram com o poeta e, pouco a pouco, surgiram, aqui e ali, manuscritos seus. No livro de poesias de D. Lygia de Araújo Lima encontramos quatro poemas manuscritos autógrafos de Honório Armond, um dos quais considerado inédito até quase o final do trabalho, quando o localizamos publicado em periódico, conforme atesta um precioso caderno de recortes, organizado inicialmente por um irmão do poeta. Esse caderno, que nos chegou às mãos por intermédio do jornalista Sérgio Ayres, casado com uma neta de Honório Armond, reúne um grande material publicado de e sobre ele poemas, artigos, informações, notícias, homenagens - de 1914 a 1951. O mesmo jornalista, grande colaborador que tivemos em Barbacena, ofereceu-nos também três poemas manuscritos e assinados pelo poeta, dois deles datados de abril e setembro de 1958, ano de sua morte. Foram certamente suas últimas produções poéticas, de cujos manuscritos certamente não teve tempo de se desvencilhar.

Além desse importante material, Sérgio Ayres nos brindou com um documento que se revelou fundamental, não só por sua importância intrínseca, como também pelas pistas que nos forneceu. Trata-se de uma carta de Guimarães Rosa a Honório Armond, em papel timbrado da Secretaria de Estado das Relações Exteriores e datada de 19 de janeiro de 1935. Rosa nela transcrevia dois poemas em francês que o poeta lhe tinha dedicado e oferecido e dos quais, em seu habitual desligamento, não tinha guardado cópia, solicitando-a, pois, ao amigo. Essa carta abriu-nos perspectivas promissoras: se Honório Armond nada guardou dos seus manuscritos, é sabido que Guimarães Rosa tudo guardava, tendo constituído um vasto e minucioso arquivo, atualmente sediado no Fundo Guimarães Rosa do IEB (Instituto de Estudos Brasileiros) da Universidade de São Paulo. Lá encontramos de fato os manuscritos autógrafos de seis poemas de Honório Armond, dois dos quais inéditos - justamente os que tinham sido oferecidos a Rosa -, além de uma carta e um bilhete do poeta. 
A recensio ou coleta de dados completou-se assim com o acréscimo de um considerável número de poemas publicados em periódicos e de manuscritos autógrafos, que forneceram importantes subsídios para a elucidação de erros tipográficos e termos ilegíveis. Além disso, a possibilidade de uma análise comparativa de poemas veiculados por mais de uma fonte, seja ela impressa ou manuscrita, revelou a existência de inúmeras variantes, que foram devidamente anotadas. Tais variantes permitem ao leitor detectar alguns indícios da gênese de alguns poemas, os diversos estados pelos quais passaram até chegarem à forma preferida pelo autor.

Como exemplo, cito o poema "Falando às sombras", de Perante o Além, comparando-o com duas outras versões, publicadas no jornal Cidade de Barbacena, em 1919 e em 1958, portanto, com um intervalo de 39 anos. A versão que consta do livro é a que se segue:

"Falando às sombras"

"Vós que passais, nas trevas esbatidas respondei-me, afinal!... por que viver? Não seria melhor termos as Vidas na insensibilidade do Não-Ser?

Dize-o tu: quem te abriu essas feridas? foi a Dor? foi o Amor? foi o Dever? Por que, e a que te vais, se te suicidas? Donde, e a que vens, ó tu que vais nascer?" ...e essas, a quem chamei, Filhas do pânico, que eu costumo invocar nesses momentos em que se ouvem, pelo ar, vozes do Além,

pareciam fazer-me, em tom vesânico, movendo lentamente os lábios lentos, este convite de sossego: Vem!

Este poema havia sido publicado em Cidade de Barbacena, em 6/4/1919, com as seguintes variantes, aqui marcadas em negrito: 
"Falando às sombras"

A Carlos Moura,

O.D.C.

"Vós que passais, nas trevas esbatidas, respondei-me, afinal!... por que sofrer?

Não seria melhor termos as Vidas

na insensibilidade do Não-Ser?

Dize tu: quem te abriu essas feridas? foi a Dor? foi o Amor? foi o Dever?

Por que te vais, ó tu que te suicidas?

Donde, e a que te virás, ó tu que vais nascer?"

...e essas, que eu invoquei, Filhas do pânico, que eu costumo invocar nesses momentos em que se ouvem, pelo ar, vozes do Além,

pareciam fazer-me, em tom vesânico, movendo brutamente os lábios lentos, este convite de sossego: Vem!

(Do livro Os caminhos da Vida e do Destino)

A versão da edição de 1921, como se pode verificar, apresenta algumas importantes modificações em relação à publicação de 1919:

- a dedicatória foi eliminada;

- na $1^{\text {a }}$ estrofe, o verbo "sofrer" é substituído por "viver", mais abrangente e adequado, uma vez que a opção do Não-Ser é inviável;

- na $2^{\underline{a}}$ estrofe, o verbo "dizer" é acrescido de seu objeto direto e faz-se um pequeno jogo com o verbo "ir", que modifica sensivelmente o sentido dos versos: se na $1^{\underline{a}}$ versão (Cidade de Barbacena), a questão incide sobre a razão do suicídio, na $2^{\text {a }}$ (Perante $O$ Além), a essa interrogação acrescenta-se outra: para onde vais?

- no $4^{-}$verso da mesma estrofe, o estranho "a que te virás" é substituído por "a que vens";

- no $1^{\circ}$ terceto, o verbo "invoquei" do $1^{\circ}$ verso, repetido no $2^{\circ}$, na 
versão de 1919, é substituído por "chamei" e, no terceto seguinte, o advérbio "brutamente", bastante inapropriado, pela forma mais aceitável "lentamente";

- para terminar, a informação de que o poema faria parte de um projeto anterior de livro, intitulado Os caminhos da Vida e do Destino é eliminada, visto estar incluído agora em outro livro.

Esse mesmo poema foi republicado em Cidade de Barbacena, em 16/10/1958, menos de dois meses antes da morte do poeta e sofreu mais algumas modificações, abaixo assinaladas:

"Falando às sombras"

"mors quies laborum ac miserarium; sæpe eum viri fortes libenter oppitiverum" (M. T. Cícero)

"Vós que passais, nas trevas esbatidas, respondei-me, afinal!... por que viver? Não seria melhor termos as Vidas na intemporalidade do Não-Ser?

Dize-o tu: quem te abriu essas feridas?

foi o Ódio? foi o Amor? foi o Dever?

Onde e a que [te] vais, ó tu que te suicidas?

Donde vens, ó tu que vais nascer?"

...e essas, a quem chamei,Filhas do pânico, que [eu] costumo invocar nesse momentos em que se ouvem, pelo ar, vozes do Além,

pareciam fazer-me, em tom vesânico,

- segredo que rompeu Selos e Portas este convite ao sono eterno: - Vem!

Nessa terceira versão, Honório Armond introduz, no espaço liminar antes ocupado pela dedicatória, uma epígrafe de Cícero, cuja tradução é: "morte, descanso dos sofrimentos físicos e das misérias; frequentemente os homens fortes de bom grado a encaram". Apoiado nessa citação de autoridade, o poeta vê a sua aspiração ao Não-Ser sob outro ponto de vista, não mais pelo desejo de uma regressão impossível, mas pela aceitação da morte que se aproxima e 
que lhe permitirá enfim sair do tempo. A intemporalidade, mais abrangente que a insensibilidade, lhe é preferível. A razão do suicídio não mais interessa, mas somente o que vem após a morte, assim como o que vem antes da vida, para aquele que nela ainda não chegou. O ódio substitui a dor das feridas e o convite ao sossego enuncia-se claramente como convite ao sono eterno. O segundo verso do último terceto foi inteiramente modificado, talvez pela insatisfação do poeta com a repetição instaurada pelo advérbio (lentamente) e o adjetivo (lentos), talvez pela aproximação física do mistério da morte. Não me parece, entretanto, que a substituição tenha sido muito feliz.

No que toca aos manuscritos obtidos, alguns rascunhos indicam que o modo de composição de Honório Armond não comportava muitas rasuras, o poema já vinha praticamente pronto. Entretanto, é possível detectar pequenas correções em alguns manuscritos, como no de "Uma nuvem no ocaso...", um de seus últimos poemas, publicado em Cidade de Barbacena em 18 de maio de 1958.

"Uma nuvem no ocaso..."

Viste, acaso, um suavíssimo Poente

de cinza e rosa, em gamas merencórias,

iluminar-se inesperadamente

numa rajada de clarões e glórias?

...uma nuvem pequena, alta e morrente, lembrando auroras, madrugadas flóreas, foi tocada do Sol, subitamente, e eis que rutila em chamas ilusórias...

Há de, em breve, apagar-se ao vir a treva que, a lento e lento, coleante adensa, amortalhando o céu crepuscular,

Mas, ao sumir-se no bulcão que a leva, que sonhos trouxe!... que ternura imensa!... quanta saudade reflorindo ao luar!...

O rascunho do poema revela, em suas rasuras e substituições, o trabalho do poeta sobre o texto, suas hesitações e decisões: 
Homir nvien mo Ceaso...

Viste, acaso, un suavissiono Poule

de cingar e rosa, en qums onerencíaris,

ihminar-x, immeenetamente, numi najide of claroes e glainas?

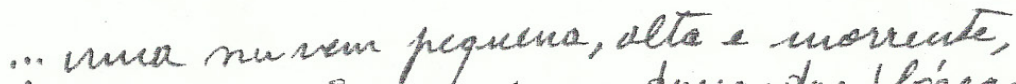

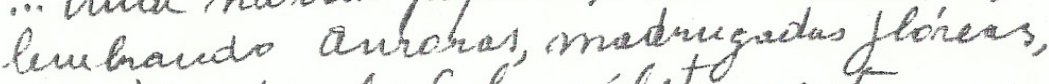
fri Focadr do sol, pirbitimenta, e. cis que nutilu en chamas ibusinis..

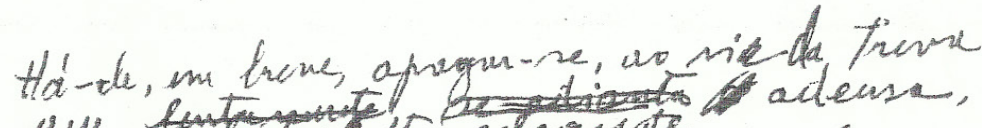

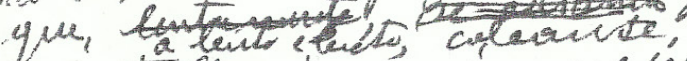

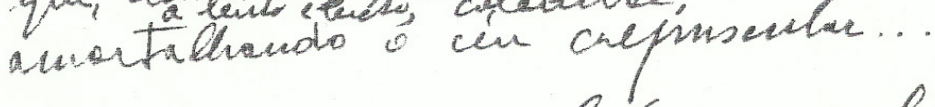

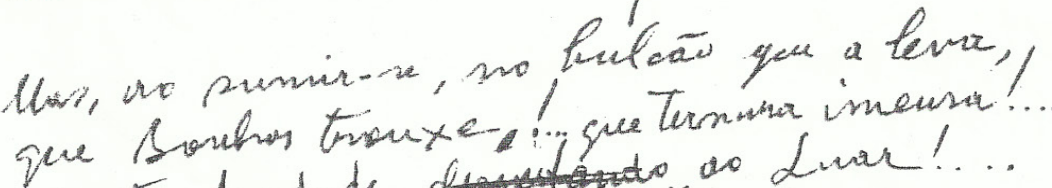

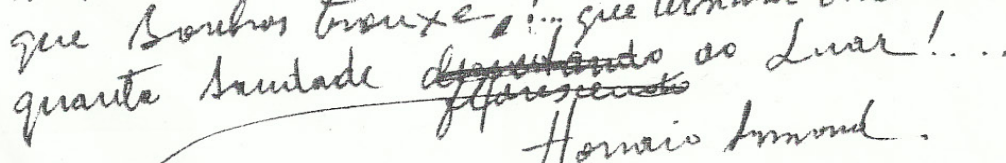

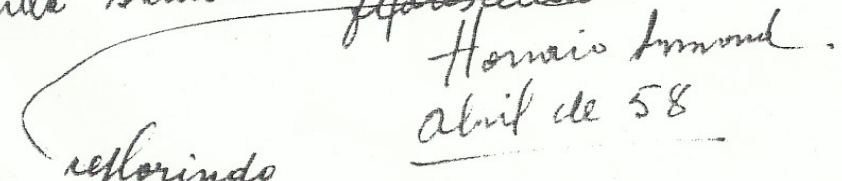

No $1^{\circ}$ verso do $1^{\circ}$ terceto ("Há de, em breve, apagar-se, ao vir a treva") percebe-se o acréscimo de um d ao artigo a: "ao vir da treva". O $2^{\circ}$ verso do mesmo terceto, inicialmente apresentava a seguinte forma: "que, lentamente, se adianta e adensa", parcialmente rasurada e substituída por "a lento e lento, coleante, adensa”. E o gerúndio do último verso do $2^{\mathrm{o}}$ terceto, cuja forma definitiva é "quanta saudade reflorindo ao luar!...", passou por duas escolhas anteriores: a primeira forma, no espaço da linha, é "despertando", rasurada e substituída, na entrelinha, por "florescendo", por sua vez também rasurada, dando lugar, num espaço já extratextual, abaixo da assinatura e da data, a "reflorindo". 
Um futuro estudo das rasuras, supressões, substituições e correções feitas nos manuscritos localizados traria certamente interessantes informações sobre as escolhas do poeta, sobre seu modo de composição do poema.

Encerrada a coleta dos poemas de Honório Armond, foram estabelecidos os critérios que deveriam nortear a nova edição, tais como: atualização ortográfica; intervenções na pontuação com o objetivo de tornar mais claras as relações sintagmáticas entre os segmentos textuais, mas sempre com o cuidado de respeitar o ritmo e as características estilísticas do poema. Nessa perspectiva, foram preservadas as maiúsculas, largamente utilizadas pelo poeta e, de resto, preconizada pela poética simbolista em que se embasava sua prática poética. Entretanto, quando ocorriam em termos com função meramente denotativa, preferiu-se o uso de minúsculas.

Estabelecido o texto e anotadas as variantes, passou-se à elaboração do aparato crítico. Foi organizado um glossário em português, imprescindível em razão do gosto parnasiano do poeta por termos raros, eruditos ou científicos. Tendo em vista a forte presença do latim em sua poesia, o que testemunha igualmente a adesão de Honório Armond à estética fin de siècle, tornou-se necessário elaborar um glossário de expressões latinas, para cuja tradução contamos com a valiosa contribuição do professor Antonio Martinez Resende. No final de cada parte foram acrescentadas notas explicativas, traduções de termos estrangeiros e outros adendos.

Como última tarefa, passamos à redação dos ensaios críticos que abordaram ambos a questão da importante intertextualidade subjacente à poesia de Armond.

Em "Afinidades eletivas: intertextos na poesia armondiana", a professora Nancy Mendes faz uma aprofundada análise do poema "Solvent Sæcula", onde detecta a teia de vozes que nele se entrelaçam e dialogam com o poeta. Entre elas sobressai a de Edgar Allan Poe, em seu "O corvo", citado e encenado no poema de Armond. Mas ouve-se aí também a voz angustiada do português Antero de Quental, a sussurrar o verso "O Corcel Negro é a morte... O Cavaleiro, o Amor!", do soneto "Mors-Amor", citação aproximada, adaptada, como se feita de memória.

No poema "Solvent Sæcula", são também convocados poetas brasileiros com os quais Armond reconhece afinidade: Hermes Fontes, seu "velho irmão de sonho", com quem o poeta compartilha o fascínio e a exaltação da morte, e Augusto dos Anjos, por sua entonação inconfundível e pela concepção monista do universo. 
No ensaio "Conflito e conciliação. Bilinguismo na poesia de Honório Armond", exploro em particular o intertexto francês implícito e explícito na obra do poeta e a função que essa língua exerce nela. A marca de Baudelaire e seu pessimismo ético permeiam toda a sua poesia, mas a aproximação com o poeta francês chega a seu ponto máximo no poema "A um cadáver", quase uma outra versão - e ainda mais crua - de "Une Charogne". Outros poetas franceses se fazem presentes à obra de Honório Armond, como Sully-Prudhomme, em seu culto parnasiano pela forma e pela ciência, e Leconte de Lisle, que busca nos mitos clássicos e bárbaros uma saída para o impasse da civilização ocidental.

O caráter de universalidade assumido pela literatura francesa na segunda metade do século XIX e início do XX deu origem ao surgimento, em diversos países, inclusive o Brasil, de uma produção literária em francês, língua que se torna sinal de erudição. Não é esse o caso de Honório Armond. Seu livro Les Voix et les Bonheurs (As Vozes e as Venturas) forma um conjunto perfeitamente orquestrado, rigorosamente codificado, composto de 14 sonetos que se subdividem em dois segmentos de 7 poemas: "Les Voix" (as Vozes) e "Les Bonheurs" (as Venturas). Vale ressaltar a forte carga esotérica e simbólica do número 7 e de sua duplicação em 14, que corresponde ao número de sonetos que compõem o livro e ao número de versos de cada soneto.

Como se viu, outras línguas se fizeram presentes à poesia de Honório Armond, em especial o latim dos paratextos: títulos, epígrafes, dedicatórias. Bem diferente é a função do francês, que ocupa o espaço propriamente textual e instaura um bilinguismo na escrita armondiana, onde exerce uma função específica: a de permitir o afloramento de uma outra persona poética. Se a língua materna é, para o poeta, lugar de dúvida, de conflito e contestação, de embate de ideias, o francês, na sua opacidade de língua estrangeira, lhe oferece um refúgio, um esconderijo secreto, onde ele depõe as armas e repousa, embalado pela musicalidade da língua.

\section{Honório Armond's complete poetry: the 2011 edition}

Abstract: This article reports the editorial process of Poesia completa de Honório Armond (Honório Armond's complete poetry), published in 2011. The poet was born in Barbacena, in Minas Gerais, in the late 19th century. His poetry's edition was made by Eliana Scotti Muzzi and Nancy Maria Mendes.

Keywords: Brazilian poetry, Symbolism, Parnassianism, Honório Armond. 